\title{
Farklı Kişniş (Coriandrum sativum L.) Popülasyon ve Çeşitlerinde Sıra Arası Mesafesinin Tarımsal Özellikleri ve Sabit Yağ Oranına Etkisi
}

\author{
Mehmet Necat İGI $\dot{I}^{1}$ \\ ${ }^{1}$ Mardin Artuklu Üniversitesi . Kızıltepe Meslek Yüksekokulu . İstasyon-Mardin \\ $\triangle$ : necatizgi@hotmail.com .
}

Geliş (Received): 04.11.2017

Kabul (Accepted): 15.12.2017

\begin{abstract}
ÖZET: Kişniş, taze yaprak ve olgun meyveleri kullanılan önemli bir baharat bitkisidir. Mevcut çalışmada tescilli Arslan ve Erbaa çeşitleri ile Mardin ilinde, özellikle ova şartlarında yaygın olarak ekilen ve halk arasında Suriye kişnişi olarak bilinen yerel popülasyonun iki farklı sıra arası $(17-34 \mathrm{~cm})$ mesafesinde ekiminin verim ve toplam sabit yă̆ oranlarına etkisi araştırılmıştır. Çalışma 2015-2016 vejetasyon yılında Mardin ekolojik koşullarında tesadüf bloklarında bölünmüş parseller deneme desenine göre yürütülmüştür. Denemede ana parseller sıra arasını, alt parseller ise çeşitleri oluşturmuştur. Olgunlaşma dönemine gelen bitkilerde hasat öncesi bitki boyu, dal sayısı, şemsiye sayısı değerleri belirlenmiştir. Hasat edilen bitkilerin verimleri ile meyve sabit yağ oranları belirlenmiştir. Deneme sonucunda yă̆ oranları hariç, çeşitler arasında bir fark görülmemiştir. Farklı sıra arası mesafesi ise dal sayısı ile verimi önemli derecede etkilemiş ve $17 \mathrm{~cm}$ sıklıkta ekilen bitkilerden daha yüksek meyve verimi (222 kg da-1) alınmıştır.
\end{abstract}

Anahtar Kelimeler: Kişniş, Coriandrum sativum L., sıra arası, verim, sabit yăg

\section{Agricultural Properties of Row Spacing Distance in Different Coriander (Coriandrum sativum L.) Populations and Varieties and Its Effect on Fixed Oil Rate}

\begin{abstract}
Coriander, fresh leaves and ripe fruits of which are used widely, is a substantial spice plant. In the current study, it was investigated that the effects of planting with two different row spacing's $(17-34 \mathrm{~cm})$ distance on the yield and total fixed oil ratios in the certified Arslan and Erbaa varieties and the local population which is widely planted in the steppe conditions and commonly known as Syrian Coriander. The study was carried out according to the experimental design of sectioned parcels in random blocks in the ecological conditions of Mardin in 2015-2016 vegetation year. In the experiment, the main parcels formed row spacing's and the sub-parcels formed varieties. Plant height, number of branches and number of umbels were determined before harvest in the plants that reached maturity period. The yields of the harvested plants and the fixed fat ratios of fruits were determined. As a result of the experiment, there was no difference between the varieties except the fat ratios. The distance between the different rows affected significantly the yield and the number of branches and the plants cultivated at $17 \mathrm{~cm}$ intervals yielded more fruit (222 kg da-1).

Keywords: Coriander, Coriandrum sativum L., row spacing, yield, fixed oil
\end{abstract}

\section{GİRIS}

Kişniş, Apiaceae familyasına ait tek yıllık otsu, kazık köklü bir ilaç-baharat bitkisidir (Şarer, 2004). Kişniş bitkisi dünyanın birçok yerinde meyvesi ve uçucu yağı için üretimi yapılan bir kültür bitkisidir. Kişniş Akdeniz bölgesinin doğal bitkisi olup, ayrıca Bangladeş, Hindistan, Rusya, Orta Avrupa'da da doğal yayılış göstermekte ve kültürü yapılmaktadır (Diederichsen, 1996; Dhanapakiam ve ark., 2008 and Bhuiyan ve ark., 2009).Ülkemizde ise Mardin, Gaziantep, Burdur, Erzurum, Denizli ve Konya gibi illerimizde üretimi yapılmaktadır (Kızıl ve İpek, 2004). Bitki sıklığı, verim ve kalite üzerinde etkili olan önemli bir yetiştiricilik uygulaması olarak kabul edilmektedir. $\mathrm{Bu}$ nedenle kişniş tarımının yapıldığı farklı bölgeler için en uygun bitki sıklığını belirlemek amacıyla araștırmalar yürütülmeye devam edilmektedir (Katar, 2015). Ülkemizde, kişnişte sıra arası mesafesi üzerine; Kızıl ve İpek (2004) Diyarbakır koşullarında, Tunçtürk (2011) Van'da, Karadoğan ve Oral (1994) Erzurum koşullarında çeşitli çalışmalar yürütmüşlerdir.

Mardin ilinde yürütülen çalışmada Arslan ve Erbaa çeşitleri ile Mardin ilinde, özellikle ova şartlarında yaygın olarak ekilen ve halk arasında Suriye kişnişi olarak bilinen yerel popülasyonun iki farklı sıra arası $(17-34 \mathrm{~cm})$ mesafesinde ekiminin verim öğeleri ve toplam sabit yağ oranlarına etkisi araştırılmıştır.

\section{MATERYAL ve METOT}

\section{Materyal}

Denemede materyal olarak Türkiye'de tescil edilen Arslan, Erbaa ile özellikle ova şartlarında ekimi yaygın olan ve halk arasında Suriye kişnişi olarak adlandırılan populasyon kullanılmıştır. Arslan ve Erbaa çeşitleri Çukurova Üniversitesi Ziraat Fakültesi Tarla Bitkileri Bölümü'nden, Suriye popülasyonu ise Suriye sınırında üretim yapan bir çiftçiden temin edilmiştir.

\section{Metot}

Çalışma 2015-2016 yılları, Kasım-Haziran ayları vejetasyon döneminde Mardin ovası ekolojik koşullarında yürütülmüştür.

Denemenin kurulduğu alanın iklim verilerine bakıldığında; yıllık ortalama düşen yağış miktarı 648 mm'dir. Sıcak ve 1lıman bir iklim hakimdir. Mardin kış 
aylarında yaz aylarından çok daha fazla yağış düşmektedir. Mardin ilinin yıllık ortalama sıcaklığg 16.6 $\mathrm{C}^{\circ}$ ' dir. Ağustos ayı $0 \mathrm{~mm}$ yağışla yılın en kurak ayıdır. Ortalama 106 yağış miktarıyla en fazla yağış Ocak ayında görülmektedir.

Deneme, tesadüf bloklarında bölünmüş parseller deneme desenine göre yürütülmüştür. Denemenin yürütüldüğü tarla pullukla sürüldükten sonra ekim öncesi ikileme yapılarak toprak ekime hazırlanmıştır. Ana parsellere sıra arası mesafe, alt parsellere çeşitler denenmiştir. Her bir parselin boyu $3 \mathrm{~m}$ olup eni ise 5 sıralı oluşturulduğu için sıra arası mesafeye bağlı olmak üzere $17 \mathrm{~cm}$ için $2.04 \mathrm{~m}^{2}, 34 \mathrm{~cm}$ için ise $4,08 \mathrm{~m}^{2}$ olarak düzenleme yapılmıştır. Çalışmada, 3 farklı kişniş çeşidine (Suriye, Arslan, Erbaa) 2 farklı sıra arası mesafe $(17 \mathrm{~cm}, 34 \mathrm{~cm})$ uygulanmıştır. Araştırmada bloklar arasında $2 \mathrm{~m}$, parsel aralarında ise $1 \mathrm{~m}$ mesafe bırakılmıştır.

Araştırmada $5 \mathrm{~kg} \mathrm{da}^{-1}$ fosforlu gübre tüm parsellere ekimle birlikte, $5 \mathrm{~kg} \mathrm{da}^{-1}$ azotlu gübre ise yarısı ekim ile birlikte, diğer yarısı ise sapa kalkma döneminde verilmiştir. Deneme sulu şartlarda yürütülmüş, yağ1ş durumu, hava sicaklığı ve topraktaki nem durumu dikkate alınarak sulama $6 \mathrm{kez}$ yağmurlama şeklinde ve yabancı ot kontrolü amaciyla $2 \mathrm{kez}$ çapalama ve $2 \mathrm{kez}$ elle yolma işlemi yapılmıştır.

Olgunlaşma dönemine gelen bitkilerde hasat öncesi her parselde kenar tesirleri hariç, rast gele seçilen 10 bitkide, bitki boyu $(\mathrm{cm})$, dal sayısı, şemsiye sayısı değerleri ölçülmüştür. Hasatta yanlardan birer sıra, başlardan ise $0.5 \mathrm{~m}$ kenar tesiri olarak atıldıktan sonra bütün gözlemler sıra aralığına göre $17 \mathrm{~cm}$ için $0.51 \mathrm{~m} \mathrm{x}$ $2 \mathrm{~m}=1.02 \mathrm{~m}^{2}, 34 \mathrm{~cm}$ için $1.02 \mathrm{~m} \mathrm{x} 2 \mathrm{~m}=2.04 \mathrm{~m}^{2}$ üzerinden yapılmıştır.

Hasat edilen bitkiler harmanlanıp dekara meyve verimleri hesaplanmıștır. Hasat sonunda her parselden, ögütülen $10 \mathrm{~g}$ meyve örneğinin uçucu yağları alındıktan sonra meyve posalarında Soxhlet yöntemi (sıcak ekstraksiyon) kullanılarak belirlenmiştir. $10 \mathrm{~g}$ ögütülmüş posa örnekleri n-hekzan yardımıyla 4 saat boyunca sicak ekstraksiyona tabi tutularak \% sabit yağ oranı belirlenmiştir.

Çalışmadan elde edilen veriler SPSS paket programında analiz edilmiş olup, analiz sonuçları asgari öneme göre yorumlanmıştır.

\section{BULGULAR ve TARTIŞMA}

Kişniş bitkisinin verim ve kalite özellikleri, üretimde kullanılan varyetenin genotipi, üretimin yapıldığ bölgenin iklim ve toprak koşulları ve yetiştiricilik uygulamaları tarafindan belirlenmektedir (Rahnavard et al., 2010 and Moosavi, 2012).

Üç farklı kişniş (Coriandrum sativum L.) türü ve iki farklı sıra arası ekim mesafesinin denendiği çalışmada; incelenen bitki boyuna ilişkin değişim tablosu Çizelge 1' de, ana dal sayısı değişim tablosu Çizelge 2' de, şemsiye sayısı değişim tablosu Çizelge 3' te, meyve verimi değişim tablosu Çizelge 4' te ve sabit yağ oranları değişim tablosu Çizelge 5' te verilmiştir.

\section{Bitki Boyu}

Çizelge 1'de görüldüğü gibi Suriye, Arslan ve Erbaa çeşitlerinde bitki boyları arasındaki farklılıklar istatistiksel olarak önemsiz bulunmuştur. En yüksek değer ortalaması Erbaa çeşidinde $(98.1 \mathrm{~cm})$, en düşük değer ise Arslan çeşidinde $(87.1 \mathrm{~cm})$ tespit edilmiş̧ir. Aynı konu hakkında Tunçtürk (2011), çeşitler arasındaki bitki boyu farklılıklarının çeşitler arasındaki genotipik farklılıktan kaynaklanabileceğini belirtmiştir. Gümüşçü ve ark. (2007) Konya ekolojik şartlarında (49.7- $68.7 \mathrm{~cm})$, Kan ve İpek (2002), (40.8-58.5 cm) ile Tunçtürk ve Tunçtürk (2008), (33.2-65.0 cm)' ün farklı hatlar üzerinde yaptıkları çalışmalarda bitki boyunun hat ve çeşitlere göre değişkenlik gösterdiğini bildirmişlerdir.

Çizelge 1. İki farklı sıklıkta ekilen kişniş çeşitlerinde bitki boyunun değişimi $(\mathrm{cm})$

\begin{tabular}{lccc}
\hline \multirow{2}{*}{ Çeşit } & \multicolumn{2}{c}{ Sıra arası mesafeler } & \multirow{2}{*}{ Ortalama $\left(\right.$ Çeşit) ${ }^{\text {od }}$} \\
\cline { 2 - 4 } Aslan & $\mathbf{1 7 \mathbf { c m }}$ & $\mathbf{3 4 \mathbf { c m }}$ & $\mathbf{8 7 . 1}$ \\
\hline Suriye & 94.6 & 79.5 & $\mathbf{9 2 . 0}$ \\
\hline Erbaa & 92.4 & 91.6 & $\mathbf{9 8 . 1}$ \\
\hline Ortalama (Sıra arası) & 98.9 & 97.1 & \\
\hline
\end{tabular}

öd: önemli değil

Ekim sıklığının bitki boyu üzerine etkisi istatistiksel olarak önemsiz bulunmuştur. Farklı ekim mesafeleri uygulamalarında bitki boyları ortalamaları bakımından en düşük $34 \mathrm{~cm}$ sıra aralığında $(89,4 \mathrm{~cm})$ ve en yüksek $17 \mathrm{~cm}$ sıra aralığında $(95,3 \mathrm{~cm})$ elde edilmiştir.

Tunçtürk (2011)' ün, ekim mesafeleri azaldıkça bitki boyunun arttığına dair bulguları ile araştırma sonuçlarımız paralellik göstermektedir. Fakat Kan ve İpek (2002), Turhan ve ark. (2005) ile Avcı ve ark. (2005)' nın bildirdikleri ekim mesafesi arttıkça bitki boyu değerlerinde de paralel bir şekilde artış olduğuna dair araştırma sonuçları çalışma bulgularımızdan farklılık göstermiştir. Üretimde kullanılan varyetenin genotipi, üretimin yapıldı ğ bölgenin iklim ve toprak koşulları ve ayrıca yetiştiricilik uygulamaları tarafından belirlenmektedir.

\section{Ana Dal Sayısı}

Üç farklı kişniş (Coriandrum sativum L.) türü ve iki farklı sıra arası ekim mesafesinin denendiği çalışmada incelenen ana dal sayısına ilişkin değişim tablosu Çizelge 2' de verilmiştir. Çizelge 2 incelendiğinde, çeşitlerin ana dal sayıları arasındaki farklılıklar istatistiksel olarak önemsiz bulunmuştur. Denemede en yüksek ana dal sayısı (7.6 adet/bitki) Erbaa çeşidinden, en düşük ana dal sayısı ise (6.2 adet/bitki) Arslan çeşidinden tespit edilmiştir. Farklı kişniş çeşitleri 
üzerine, yaptığı iki yıllık çalışmasında Tunçtürk (2011) ana dal sayısını en yüksek Gürbüz çeşidinden (5.84-6.71 adet/bitki), en düşük Arslan çeşidinden olduğunu (5.80$6.43 \mathrm{adet} / \mathrm{bitki}$ ) tespit etmiştir. Yine kişnişte farklı hat ve çeşitlerde yapılan çalışmalarda ana dal sayısını, Kan ve İpek (2002), 3.8-5.8 adet/bitki, Kaya ve ark. (2000), 3.77.7 adet/bitki, Tunçtürk ve Tunçtürk (2008), 5.3-5.9 adet/bitki arasında tespit etmişlerdir.

Farklı ekim mesafelerinin ana dal sayısı üzerine etkisinin önemli olduğu tespit edilmiştir. Farklı ekim mesafeleri uygulamalarında en yüksek $34 \mathrm{~cm}$ sira aralığında (7.6 adet/bitki), en düşük $17 \mathrm{~cm}$ sıra aralığında (6.7 adet/bitki) elde edilmiştir. Araştırma sonucuna göre, sıra arası mesafe artışına paralel bir şekilde ana dal sayısında artış olduğu görülmüştür. Aynı şekilde farklı ekim sıklığı $(20,30,40,50 \mathrm{~cm})$ çalışması ile Tunçtürk (2011)' ün, sıra arası mesafe arttıkça ana dal sayısının da arttığına dair çalışma bulgularıyla uyumludur.

Çizelge 2. İki farklı sıklıkta ekilen kişniş çeşitlerinin bitkide ana dal sayısı değerleri (adet/bitki)

\begin{tabular}{lccc}
\hline \multirow{2}{*}{ Çeşit } & \multicolumn{2}{c}{ Sıra arası mesafeler $(\mathbf{c m})$} & \multirow{2}{*}{ Ortalama $\left(\right.$ Çeşit) $^{\text {öd }}$} \\
\cline { 2 - 4 } & $\mathbf{1 7 \mathbf { c m }}$ & $\mathbf{3 4 \mathbf { c m }}$ & $\mathbf{6 . 2}$ \\
\hline Aslan & 6.1 & 6.3 & $\mathbf{6 . 8}$ \\
\hline Suriye & 5.6 & 8.0 & $\mathbf{7 . 6}$ \\
\hline Erbaa & 6.7 & 8.4 & \\
\hline Ortalama (Sira arası) & $\mathbf{6 . 1}^{\mathbf{b}}$ & $\mathbf{7 . 6}^{\mathbf{b}}$ & \\
\hline
\end{tabular}

öd: önemli değil; *:p<0.05

\section{Şemsiye Sayıs}

Çizelge 3' ten de görüldüğü üzere, şemsiye sayıları bakımından çeşitler arasındaki farklılık istatistiksel olarak önemsiz bulunmuştur. En fazla şemsiye sayısı (39.7 adet/bitki) Suriye popülasyonundan, en az şemsiye sayısı (26.5 adet/bitki) ise Arslan çeşidinden elde edilmiştir. Deneme bulguları; Tunçtürk (2011)' ün çeşitlerin şemsiye sayısı üzerine yaptığ Arslan çeşidinde 10.4-12.6 adet/bitki olduğunu belirttiği değerlerin çok üzerinde olduğu görülmüştür.

Kişnişte farklı ekim sıklığının şemsiye sayısına etkisi istatistiksel olarak önemsiz bulunmuştur. En fazla şemsiye sayısı (38.6 adet/bitki) $34 \mathrm{~cm}$, en az şemsiye sayısı ise $(27.1 \mathrm{~cm}) 17 \mathrm{~cm}$ sıra aralığ uygulamalarından elde edilmiştir. Şemsiye sayısına ilişkin yapılan çalışma bulgularında; Kız1l ve İpek (2004)' in, (11.37-15.59 adet/bitki), Kan ve İpek (2002)' in (11.2-13.6 adet/bitki), Arabac1 ve Bayram (2005)' in (9.4-15.5 adet/bitki), Tunçtürk (2006)' ün (15.20- 17.26 adet/bitki), Tunçtürk ve Tunçtürk (2008)' ün (13.5-18.5 adet/bitki) ve Tunçtürk (2011)' ün (11.4-13.4 adet/bitki) belirttikleri sonuçların çok daha üzerinde olmuştur. Oluşan bu farklılığın ekolojik farklılık ve kültürel uygulamalardan kaynaklanabileceği düşünülmektedir.

Çizelge 3. İki farklı sıklıkta ekilen kişniş çeşitlerinin bitkide şemsiye sayısı değerlerinin değişimi (adet/bitki)

\begin{tabular}{|c|c|c|c|}
\hline \multirow{2}{*}{ Çeşit } & \multicolumn{2}{|c|}{ Sira arası mesafeler } & \multirow{2}{*}{ Ortalama (Çeşit) ${ }^{o d}$} \\
\hline & $17 \mathrm{~cm}$ & $34 \mathrm{~cm}$ & \\
\hline Arslan & 24.1 & 28.9 & 26.5 \\
\hline Suriye & 29.1 & 50.2 & 39.7 \\
\hline Erbaa & 28.2 & 36.8 & 32.5 \\
\hline Ortalama (Sira arasi) ôd & 27.1 & 38.6 & \\
\hline
\end{tabular}

öd: önemli değil

\section{Meyve Verimi}

En yüksek meyve verimi ortalaması Erbaa çeşidinden $\left(201.6 \mathrm{~kg} \mathrm{da}^{-1}\right)$, en düşük meyve verimi ortalaması ise Arslan çeşidinden $\left(156.8 \mathrm{~kg} \mathrm{da}^{-1}\right)$ elde edilmiştir (Çizelge 4). Kızıl ve İpek (2004); Arabacı ve Bayram (2005); Gümüşçü ve ark. (2007), Tunçtürk ve Tunçtürk (2008) ve Tunçtürk (2011) elde ettikleri bulgularda kişniş verimi değerleri 53.1 - $168.8 \mathrm{~kg} \mathrm{da}$ ${ }^{1}$ arasında olduğu görülmektedir.

Sıra arası mesafelerden ise; elde edilen en yüksek meyve verimi ortalaması $17 \mathrm{~cm}$ sira arası uygulamasından $\left(222.0 \mathrm{~kg} \mathrm{da}^{-1}\right)$, en düşük meyve verimi ortalaması ise $34 \mathrm{~cm}$ sira arası uygulamasindan $(123.0$ $\mathrm{kg} \mathrm{da}^{-1}$ ) elde edilmiştir (Çizelge 4). Araştırmada, sıra arası mesafe arttıkça meyve veriminde azalma meydana geldiği görülmüştür. Tunçtürk (2011), Turhan ve ark.(2005), Arabacı ve Bayram (2005), yaptıkları çalışmalarda, sıra arası mesafe arttıkça verimde bir azalmanın söz konusu olduğunu belirttikleri bulguları çalışma sonuçlarımızla paralellik göstermektedir. Bununla birlikte; çalıșma sonuçlarımız, Tunçtürk (2011)'ün (89.3-116.3 $\left.\mathrm{kg} \mathrm{da}^{-1}\right)$, Kan (2007)' in (71.30 $\left.\mathrm{kg} \mathrm{da}^{-1}\right)$, Kan ve İpek (2002)'in (86.6-124.3 $\mathrm{kg} \mathrm{da}^{-1}$ ) ile Avc1 ve ark. (2005)' nın (90.57-112.42 $\mathrm{kg} \mathrm{da}^{-1}$ ) elde ettikleri meyve verimi bulgularından daha yüksek olmuştur. Elde edilen bu farklılığın; ekolojik çevre, kültürel uygulamalar ve kullanılan çeşit farklılığından kaynaklandığı tahmin edilmektedir. 
Çizelge 4. İki farklı sıklıkta ekilen kişniş çeşitlerinde verim değerleri değişimi $\left(\mathrm{kg} \mathrm{da}^{-1}\right)$

\begin{tabular}{lccc}
\hline \multirow{2}{*}{ Çeşit } & \multicolumn{2}{c}{ Sıra arası mesafeler } & \multirow{2}{*}{ Ortalama $\left(\right.$ Çeşit) $^{\text {̈̈d }}$} \\
\cline { 2 - 4 } & $\mathbf{1 7 c m}$ & 121.3 & $\mathbf{1 5 6 . 8}$ \\
\hline Arslan & 192.2 & 102.3 & $\mathbf{1 5 9 . 3}$ \\
\hline Suriye & 216.3 & 145.6 & $\mathbf{2 0 1 . 6}$ \\
\hline Erbaa & 257.6 & $\mathbf{1 2 3 . 0}^{\mathbf{b}}$ & \\
\hline Ortalama (Sira aras1) & $\mathbf{2 2 2 . 0}^{\mathbf{*}}$ & & \\
\hline
\end{tabular}

öd: önemli değil; $* *: p<0.01$

\section{Sabit Yăg Orant}

Çalışmada kişniş çeşitleri arasındaki sabit yağ oranlarına etkisi istatistiksel olarak önemli bulunmuştur. Sabit yağ oranlarına ilişkin değerlere bakıldığında; en yüksek sabit yağ oranı (\%27.41) Suriye popülasyonunda, en düşük yağ oranı ise (\%23.23) Erbaa çeşidinde tespit edilmiştir (Çizelge 5). Nguyen veark. (2015), organik olarak yetiştirdiği olgun kişniş meyvelerinde yağ oranını \%25.1 ve Keskin (2016), Isparta ilinde Erbaa çeşidinde en yüksek yă oranını $\% 25.42$ olarak tespit etmişlerdir. Erbaa çeşidinde elde ettiğimiz oranın daha düşük çıkmasının sebebi ekolojik şartlar ve farklı kültürel uygulamalardan kaynaklandığ düşünülmektedir.

Farklı sıra arası ekim denemelerinin sabit yă oranlarına etkisi istatistiksel olarak önemsiz bulunmuştur. Ekim sıklığı çalışmasında en yüksek yă̆ oranı ortalaması $(\% 25.29) \quad 17 \quad \mathrm{~cm} \quad$ sira aralığı uygulamasından, en düşük yağ oranı ortalaması (\%25.23) ise $34 \mathrm{~cm}$ sira aralığ edilmiştir.

Çizelge 5. İki farklı sıklıkta ekilen kişniş çeşitlerinin meyvelerinde sabit yağ oranlarının değişimi (\%)

\begin{tabular}{lccc}
\hline \multirow{2}{*}{ Çeşit } & \multicolumn{2}{c}{ Sıra arası mesafeler } & \multirow{2}{*}{ Ortalama $\left(\right.$ Çeşit) ${ }^{* *}$} \\
\cline { 2 - 4 } & $\mathbf{1 7 c m}$ & $\mathbf{3 4 c m}$ & $\mathbf{2 5 . 1 6}$ \\
\hline Arslan & 24.85 & 25.46 & $\mathbf{2 7 . 4 1}$ \\
\hline Suriye & 27.60 & 27.22 & $\mathbf{2 3 . 2 3}$ \\
\hline Erbaa & 23.42 & 23.03 & \\
\hline Ortalama (Sıra arasi) ${ }^{o ̈ d}$ & $\mathbf{2 5 . 2 9}$ & $\mathbf{2 5 . 2 3}$ & \\
\hline
\end{tabular}

öd: önemli değil; **:p<0.01

\section{SONUC}

Mardin ili ova koşullarında yapılan kişniş çalışması sonucunda en yüksek sabit yağ oranı \%27.41 ile Suriye popülasyonundan elde edilmiştir. Farklı sıra arası mesafesi uygulamalarında ise dal sayısı ile meyve verimi önemli derecede etkilemiş ve $34 \mathrm{~cm}$ sıra aralığından, daha yüksek dal sayısı (7.6 adet/bitki), 17 cm sıklıkta ekilen bitkilerden, daha yüksek meyve verimi (222 $\left.\mathrm{kg} \mathrm{da}^{-1}\right)$ elde edilmiştir. Çalışma sonucunda, Mardin ili için, özellikle ova şartlarında kişniş tarımı için en uygun kişniş çeşidinin Suriye popülasyonu ve sıra aralığının $17 \mathrm{~cm}$ olduğu sonucuna varılmıştır. Bundan sonra yapılacak olan kişniş çalışmalarında bölge ekolojisine uygun ve yüksek sabit yağ oranına sahip Suriye popülasyonunun tercih edilmesi ve $15-20$ cm sıra aralıklarında ekilmesi önerilmektedir.

\section{TEŞEKKÜR}

Bu çalışmada yardımlarını esirgemeyen Prof. Dr. İsa Telci ve Prof. Dr. Şengül Karaman'a teşekkür ederim.

\section{KAYNAKLAR}

Arabacı O, Bayram E 2005. Farklı sira aras1 ve tohumluk miktarlarında Kişniş (Coriandrum sativum L.)' in bazı morfolojik ve teknolojik özelliklerinin belirlenmesi. Türkiye VI. Tarla Bitkileri Kongresi 59 Eylül 2005, Antalya, Araştırma Sunusu, Cilt: 1, Sayfa: 535-540.
Avc1 AB, Nia RA, Bayram E 2005. Bornova koşullarında yetiştirilen İran kökenli kişniş (Coriandrum sativum var. vulgare)' in verim ve kalite özellikleri. Türkiye VI. Tarla Bitkileri Kongresi, 5-9 Eylül 2005, Antalya. Cilt: 1, Sayfa: 477-482.

Bhuiyan MNI, Begu J and Sultana M 2009. Chemical composition of leaf and seed essential oil of Coriandrum sativum L. from Bangladesh. Bangladesh J. Pharmacol 4:150-153.

Dhanapakiam P, Joseph JM, Ramaswamy VK, Moorthi $\mathrm{M}$ and Kumar AS 2008. The cholesterol lowering property of Coriander (Coriandrum sativum L.). Mechanism of Action. J Environ. Biol. Jan;29(1):536.

Diederichsen A 1996. Coriander (Coriandrum sativum L.). ISBN 92-9043-284-5. P:1-83.

Gümüşçü A, İpek A, Gümüşçü G 2007. Tescilli kişniş (Coriandrum sativum L.) çeşitlerinin Çumra (Konya) koşullarında performanslarının belirlenmesi. Türkiye VII. Tarla Bitkileri Kongresi,. 25-27 Haziran 2007, Erzurum. Cilt: 2, S: 521-525.

Kan Y 2007. Konya ekolojik koşullarında yetiştirilen kişnişte (Coriandrum sativum L.) uygulanan organik ve inorganik gübrelerin verim ve uçucu yağ üzerine etkileri. Selçuk Üniversitesi, Zir. Fak. Dergisi, 21 (42): 36-42. 
Kan Y, İpek A 2002. Seçilmiş bazı kişniş (Coriandrum sativum L.) hatlarının verim ve bazı özellikleri. Bitkisel İlaç Hammaddeleri Top., Bil. 29-31 Mayıs 2002, Eskișehir.

Karadoğan T, ve Oral E 1994. Farklı Sira Aralıkları Uygulanan Kişniş Varyetelerinin Verim ve Verim Unsurları ve Kalitesi Üzerine Bir Araştırma. Atatürk OJ Zir.Fak.Der. 25(3), 311-318.

Katar D 2015. Ankara ekolojik koşullarında farklı ekim normlarının Kişniş (Coriandrum sativum L.) çeşitlerinin verim ve verim öğeleri üzerine etkisi. Biological Diversity and Conservation ISSN 13088084 Online; ISSN 1308-5301 Print 8/3 (2015) 173 180.

Kaya N, Yılmaz G ve Telci İ 2000. Farklı zamanlarda ekilen kişniş (Coriandrum sativum L.) popülasyonlarının agronomik ve teknolojik özellikleri. Turk J. Agric. For (24): 355-364.

Keskin $S$ ve Baydar H 2016. Umbelliferae Familyasından Bazı Önemli Kültür Türlerinin Isparta Ekolojik Koşullarında Tarımsal ve Teknolojik Özelliklerinin Belirlenmesi. Süleyman Demirel Üniversitesi Fen Bilimleri Enstitüsü Dergisi Cilt 20, Say1 1, 133-141, 2016.

Kızıl S ve İpek A 2004. Bazı kişniş (Coriandrum sativum L.) hatlarında farklı sıra arası mesafelerinin verim, verim özellikleri ve uçucu yağ oranı üzerine etkileri. Tarım Bilimleri Dergisi, 10 (3): 237-244.

Moosavi SGR 2012. Yield and yield components of Coriandrum sativum L. as affected sowing date and plant density. Technical Journal)of Engineering and Applied Sciences. 2 (4): 88-92.
Nguyen Q, Talou T, Cerny M, Evon P and Merah O 2015. Oil and fatty acid accumulation during coriander (Coriandrum sativum L.) fruit ripening under organic cultivation. Open Archive TOULOUSE Archive Ouverte (OATAO). http://oatao.univ-toulouse.fr/ . The Crop Journal, vol. 3 (n 4). pp. 366-369. ISSN 2214-5141

Rahnavard A, Sadeghi S and Ashrafi ZY 2010. Study of sowing date and plant density affect on Black Cumin (Cuminum carvi) yield, in Iran. Biological Diversity and Conservation, 3(1): 23-27.

Şarer E 2004. Seçilmiș kişniş hatlarının yazlık ve kışlık ekimin ürün kalitesine etkisi. Proje No:2000-05-03015.

Tunçtürk M 2006. Kişniş (Coriandrum sativum L.) bitkisinde farklı tohumluk miktarlarının verim ve verim özellikleri ile uçucu yağ oranı üzerine etkisi. Selçuk Üniversitesi. Ziraat Fakültesi Dergisi. 20 (39): 58-62.

Tunçtürk M, Tunçtürk R 2008. Farklı azot dozu uygulamalarının bazı kişniş (Coriandrum sativum L.) popülasyonlarında verim ve verim özelikleri üzerine etkisi. Y.Y.Ü. Fen Bilimleri Enstitüsü Dergisi. Cilt;13: Say1: 1, Sayfa: 39-44.

Tunçtürk R 2011. Kişniş (Coriandrum sativum L.) Çeşitlerinde Değişik Ekim Mesafelerinin Verim ve Kalite Üzerine Etkisi. YYÜ Tarla Bilimler Dergisi, 21(2): 89-97.

Turhan H, Afat O ve Turhan P 2005. Bitki sıklığının kişnişte (Coriandrum sativum L.) verim ve verim unsurları üzerine etkisi. Türkiye VI. Tarla Bitkileri Kongresi, 5-9 Eylül 2005, Antalya, Cilt: 1, Sayfa: 471-475. 